\title{
Antecedents of Second Order Outsourcing by Manufacturing Suppliers in Low-Cost Countries
}

\author{
Md Samim Al-Azad ${ }^{1}$, JoongHo Ahn ${ }^{1} \&$ Zhan $\mathrm{Su}^{2}$ \\ ${ }^{1}$ College of Business Administration, Seoul Nat'l University, South Korea \\ ${ }^{2}$ Faculty of Administrative Sciences, Laval University, Quebec, Canada \\ Correspondence: Md. Samim Al-Azad, College of Business Administration, Seoul Nat'l University, Gwanak gu, \\ Seoul 151-742, South Korea. Tel: 82-02-880-6840. E-mail: samim@snu.ac.kr
}

Received: April 14, 2015 Accepted: April 28, 2015 Online Published: June 13, 2015

doi:10.5539/ass.v11n16p302

URL: http://dx.doi.org/10.5539/ass.v11n16p302

\begin{abstract}
The objective of this study is to identify and understand the process and factors that influence the 'second-order' outsourcing decision in context of manufacturing firms in low cost developing countries. Usually, big manufacturing suppliers receive more foreign manufacturing orders than they can handle with their existing infrastructure, and then, transfer part of their manufacturing process to other smaller firms due to the lack of internal capabilities and production factors. This study aims to identify factors that influence large manufacturing suppliers to go for second-order sub-contracting. A simple questionnaire was developed to collect data and a total of 126 responses were collected from mid-level managers of manufacturing outsourcing suppliers. The findings revealed that access to inter-firm resources, company focus, and internal shortages of certain resources and capabilities have significant effects on second-order outsourcing decisions. Both internal and external factors influence managerial decisions and the managers need to evaluate both internal and external environment for maximizing the benefits before adopting the outsourcing as a business strategy.
\end{abstract}

Keywords: competitive advantage, critical success factors, developing countries, manufacturing firm, outsourcing

\section{Introduction}

In today's world of ever increasing competition, organizations are forced to look for new ways to generate value to survive in the global market. The world has embraced the phenomenon of outsourcing and firms have adopted its principles to help them expand into new markets (Bertrand, 2010; Quinn, 2000). This perspective holds that all activities unrelated to strategic core competencies should be transferred to third parties since economy of scale allow specialized vendors to provide services at lower costs. Although the traditional outsourcing emphasis on tactical benefits like cost reduction have recently been replaced by productivity and innovation (Mohiuddin $\&$ $\mathrm{Su}, 2013 \mathrm{a}$; Greer et al., 1999). However, Cost remains the most important challenge for manufacturing firms in the way to enhance efficiency and productivity (Rashid et al., 2014). Manufacturing firms must produce with lowest possible cost in order to be competitive in the market place and increase the market share and create added value for the shareholder. Sudden downturn in demand of products of these firms may affect firms' resources and investment as large suppliers are required to invest in their plants adequately for getting supply orders from the lead buyers from the global market. Moreover, other human and fixed capital investment in manufacturing plant may become idle that would increase the production related fixed costs and variable costs. As a consequence, these factors might lead these firms towards lower return on investment (ROI).

In order to improve the use of production capacity and proper utilization of their capacity, many firms consider outsourcing strategy as one of important strategic decisions when they are overwhelmed by the large scale supply orders from the lead buyers. Second order outsourcing allows them to reduce cost and improve profit margin, and lead them, at the same time, towards competitive position in international market (Mohiuddin \& Su, 2013b; Kotabe et al., 2004). Outsourcing non-core activities to other relatively smaller manufacturing firms at a lower operating cost is considered a cost effective way of using outside suppliers in order to satisfy suddenly increased demand from the foreign buyers. The second order outsourcing take place when the $1^{\text {st }}$ level outsourcing suppliers receive more work order than they have the managerial, infrastructural or financial resources to fulfill the contracts they signed with their clients from the large multinational lead firms in mutually 
accepted time frame. Thus second order outsourcing or sub-contracting is defined as informal sub-contracting activities that take place between large suppliers and local smaller manufacturers in a given country. This is a very interesting and important issue to analyze as the long term viability of offshore outsourcing that depends on this informal sub-contracting and root of many quality and working environment related accidents come from these para-legal factories.

Outsourcing is not a new idea, however, its current understanding started during middle of the $20^{\text {th }}$ century when some companies welcome the idea of outsourcing to less developed countries. For decades, jobs have been migrated from the developed countries to offshoring countries such as India, China, Philippines, and Bangladesh in order to minimize the production and operating cost. Cynthia A. Kroll (2004) stated that the recent wave of outsourcing includes different types of activities with different wage levels. These days, outsourcing is not only limited to a certain types of industries but also followed by all types of industries, and continually moving towards new geographic area in search of continuous advantageous locations. Aron \& Singh (2005) found that lack of internal resources and capabilities would make outsourcing strategy as an attractive and cost-effective option that let them to concentrate on core business functions (Mohiuddin, 2011). Advantages of Outsourcing are multiple (Mohiuddin \& Su, 2013a; Rashid \& Al-Azad, 2013). Some of them are lower operating cost, improved competitiveness, lower capital investment and shifting resources towards core competencies based on firm activities, generate economy of scale, explore new market, access to third parties capability, reducing risks and make idle capital available for further specialization of core competencies (Rashid \& Al-Azad, 2013).

Since the large manufacturing firms in developing countries take second-order outsourcing decision to other supplier firms, this study considers Bangladeshi manufacturing firms for exploring the research question, as Bangladesh is considered as one of top manufacturing outsourcing destinations in the world. Bangladesh manufacturing industries have grown since late $80 \mathrm{~s}$ and expanding ever since. The country is now fast moving towards manufacturing hub as the low-tech relocation is being taken place from the fast moving manufacturing countries such China and India, South-East Asia. The leading garments sectors where demand is dependent on the international market and very often volatile. In some seasons there are excess of demand and hence needs more investment in capacity building in the sector, and some other times decreasing demands in international market let the factory idle or underutilized production capacity. This cyclical reason leads firms towards the option of second order outsourcing to other smaller manufacturing firms. The results of this study could help the managers of larger manufacturing firms in developing country for making second-order outsourcing decision of their less/non-core activities to other supplier firms. The findings also could be very important for small and medium manufacturing supplier firms since they have no enough infrastructures to get order from develop country firms in a competitive market. Therefore, this study was an attempt to assess determinants influencing the second order outsourcing decision.

The main objective of this study is to analyze the factors that influence manufacturing subcontracting decision called second order outsourcing to other suppliers. Therefore, this study explores the following two research questions:

1) What are the variables that make up the firms' outsourcing decision of less/ non-core activities to others?

2) How do these variables influence large manufacturing firms second-order outsourcing decision to others suppliers in developing country?

\section{2. 'Second-order' Outsourcing in Fast Developing Manufacturing Countries}

With the expansion of business activities and complexity, the outsourcing strategy is used as a frequent or common practice among the manufacturing industries. Numerous reasons, why manufacturing firms take outsourcing decision, have been recognized by the researchers. However, previous literature mostly focused on the outsourcing decision factors from the developed country firms' perspective but given no attention on supplier side outsourcing decisions. This supplier side decision factors had not been evident in literature, where some large companies in developing countries take outsourcing decision to other suppliers. The factors which may impact on second order outsourcing decision are discussed from the broad range of perspective of developing country manufacturing firms.

No firm has all the resources that are required for manufacturing its products and services. Here, firm resources include all assets, human resources, capabilities, organizational process, firm attribute, information, knowledge, etc. controlled by a firm that enable the firm to conceive of implement strategies that improves its efficiencies and effectiveness (Daft, 1983). According to resource based vies (RBV), outsourcing can be a strategy to utilize others resources by making strategic relationship (Quinn, 2000). Besides, Cheon et al. (1995) and Al-Azad and Ahn (2014) argued that outsourcing can be described from the resource-based perspective as a strategic decision 
aiming at filling the gap between desired capabilities and actual capabilities. It could also be seen as a desire for the organization to focus on its core competence.

In high-time, the RMG firms receive more foreign contractual manufacturing orders than they can handle with their existing infrastructure. On the other hand, thousands of smaller sized firms could not get contract manufacturing directly due to their either not fulfilling the criteria of receiving manufacturing contract from foreign buyers or do not have adequate knowledge and contacts of foreign buyers. As a consequence, usually, the big manufacturing firms make 'first-order' contractual agreement with the foreign buyer, and, then they transfer their portion of manufacturing process to others small manufacturing firms to fulfill the contact in time. This kind of second order agreement may be happen due to first-order manufacturing firm's unavailability of adequate resources like human resource, IT infrastructure, insufficient production capacity, inadequate technical expert and support infrastructure and so on.

In the age of rapid technological advancement, manufacturing firms focus on reducing production costs and maintain high quality manufacturing services. For doing so, firms would need to specialize on core business activities in what they do best, and deemphasize the less/non-core activities that don't have much effect on firm's core businesses and can be procured from the best performers available in the market. Outsourcing enables the focal firms to establish outsourcing partnership like relationship with the suppliers for executing their existing business processes- better, faster, and at a lower operating cost as well as economy of scale (Mohiuddin \& $\mathrm{Su}$, 2013; Cook \& Gildner 2008). Therefore, we can define outsourcing as transferring all or part of the internal manufacturing activities to external suppliers for certain transformation and taking it back in a new form in order to re-integrate into the focal firm's production system. Davison (2006) did a survey on outsourcing firms and found that outsourcing is growing between 20 to 25 percent per annum and become an alternative way of remaining competitive in the market place. Outsourcing helps firm to increase efficiency, utilizing the own and third party capability, improve product and service quality, reduce costs, better customer supports and share risks (Mohiuddin \& Su, 2013a, 2013b; Bertrand, 2010; FAITC, 2010). In second-order outsourcing framework, manufacturing firms in developing country can handle a large volume of outsourcing order from foreign clients with the help of other suppliers by utilizing their manpower and capabilities. This may also allow them to increase their efficiency by concentrating on core activities and transferring less/non-core activities to others suppliers. Collaborating between large suppliers (first tier) and smaller suppliers (second tier/order) can enable these firms to accelerate product and process innovations, fasten finding solutions to challenging issues and gain overall competitiveness from the associative values.

According to Bhagwati, Panagariya and Srinivasan (2004), outsourcing is basically a trade phenomenon that respect trade theories and create values from trade. Rashid et al. (2014) shows that trade in intermediate inputs have grown faster than trade in finished products. While the globalization of production may yield important productivity benefits, there is a widespread view that it has also adversely affected low skilled workers. There are frequent media reports on how low-skilled labors in the developed countries are hurt when manufacturing jobs are relocated to the low cost countries (LCC). During the financial crises, general opinion on job losses goes against outsourcing to developing countries without examining the real value that this strategy creates for the focal firm (Hsieh \& Woo, 2005; Hummels et al., 2001; Islam et al., 2014). In reality, outsourcing debates has shifted from Make vs. Buy towards Make vs. allay and from cost related issue to having access to complementary resources that render focal firm more competitive, efficient and flexible and allow to create economy of scale with second order outsourcing (Mohiuddin, 2011).

In second order outsourcing the cost factor is relatively less important than having access to manufacturing infrastructure so that the delay and quality of the product can be kept as promised with the lead buyers from large markets such as USA, Canada and European Union. The locations for off-shoring were growing especially in the Asian region such as India, China, Malaysia and Bangladesh. Although cost savings was still a very important consideration factor (Mohiuddin, 2011; Abidi et al., 2011), companies were outsourcing for other reasons as well. Literature review shows that the top ten reasons why companies would outsource are as follows: Reduce and control operating cost, Improve company focus, Gain access to world class capability, Free resources for other purposes, Resources are not available internally, Accelerate re-engineering benefits, Non-core function that is too complex to manage, Make capital funds available, Share risks, and Cash Infusion. There were also reasons companies outsource due to lack of technology capability, strategic advantage to the companies, better service quality vendor and sound contract, lack of internal capacity in meeting production ramp demand and also possible limited space for expansion. 


\section{Research Design \& Hypothesis Development}

\subsection{Theoretical Framework}

For constructing the conceptual model, we extensively review the previous literature and identified various outsourcing decision factors that influence the develop country manufacturing firms for outsourcing their activities to developing country manufacturing firms. These factors are, to a large extent, can be applied to Bangladeshi manufacturing firms to analyze their second-order outsourcing decision to other suppliers. In this study, we take into consideration four main outsourcing factors (ten sub factors) as independent variables that are mostly cited in the literature and related to our study objectives. These four factors which influence the decision of second-order outsourcing decisions are operating cost reduction, improve company focus, access to missing capability and internal resources constrains. The only one dependent variable of our study is second-order outsourcing decision. The research framework is shown as Figure 1 below.

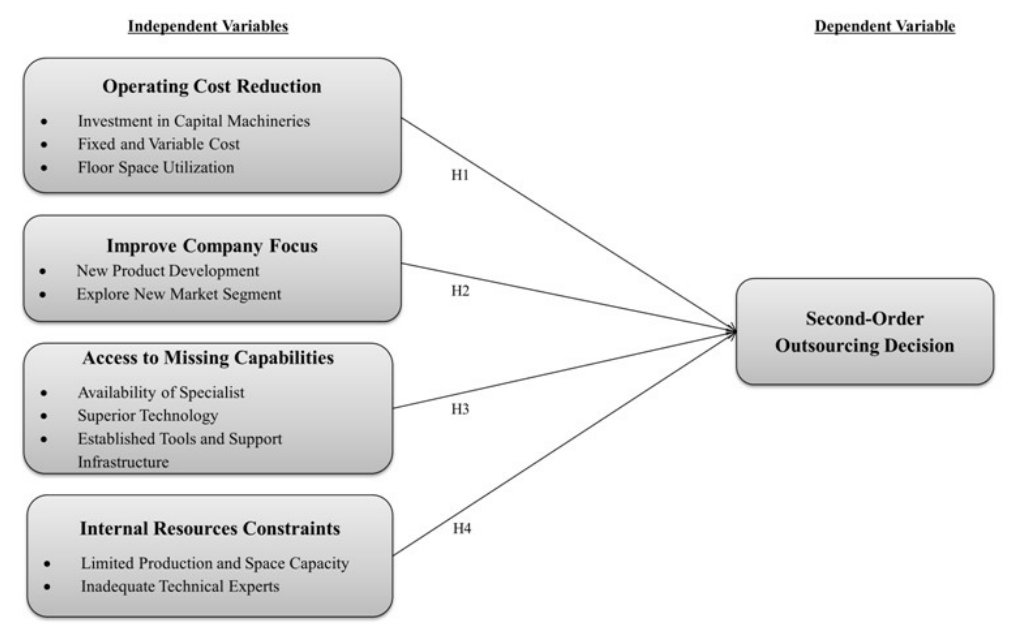

Figure 1. Proposed research framework

\subsection{Hypothesis Development}

\subsubsection{Operating Cost Reduction}

Reducing operating cost is one of the most cited factors in the literature that influences manufacturing firms to outsource part of activities to suppliers. The main motivation behind outsourcing is to reduce primary capital investment, space expenditure, and fixed and variable costs (Rashid \& Al-Azad, 2013). Through outsourcing manufacturing firms can reduce operational cost and investment in plant and investment (Bettis et al., 1992), therefore, this variable proposes three components (such as investment in capital machineries, fixed and variable cost and floor space utilization) of hypotheses that allow firms to reduce operating cost related to manufacturing process.

1) Investment in Capital Machineries

Capital investment refers to the degree to which a firm invests in a manufacturing plant to purchase land, machinery, and buildings to produce goods and services. By outsourcing non-core activities, certainly, firms could save some portion of capital investment and at the same time they are allowed to invest this amount to core business activities, thus improving specialization (Claver et al., 20002). Moreover, the savings could be re-invested in R\&D for New product development (NPD) and innovation. Consequently, we can propose the following hypothesis.

Hypothesis H1.1: Reduced Investment in capital machineries has influence in second-order outsourcing decision.

2) Fixed and Variable Cost

A fixed cost refers to an expenditure that does not vary as a function of production size. One the other hand, variable cost varies with production size. Like capital investment, reduction in fixed and variable costs are also important considerations when a firm decides whether to engage in an outsourcing strategy. Lau and Zhang (2006) found that outsourcing turns fixed costs into variable costs, for example, instead of hiring full-time 
employees do activities by outside part-time employees. Outsourcing allows firms to reduce number of employees in manufacturing plant and shift employees to focus on core activities. Sen and Zhu (1996) argued that outsourcing allows a firm to save in terms of both fixed and variable cost. Consequently, we can propose the following hypothesis.

\section{Hypothesis H1.2: Reduced fixed and variable cost has influence in second-order outsourcing decision.}

\section{3) Floor Space Utilization}

Space refers to the degree to which a firm uses its factory floor to produce goods and services in manufacturing process. Outsourcing allows a firm to reduce space consumption by transferring its non-core activities to second tier factories. On the other hand, doing activities internally requires office space expenses and other costs associated with providing a work space or manufacturing setup. Consequently, we can propose the following hypothesis.

\section{Hypothesis H1.3: Floor space utilization has influence in second-order outsourcing decision.}

\subsubsection{Improve Company Focus}

By outsourcing non-core activities to third parties, companies can concentrate on their main/core activities that result in new product development and innovation in product and process. It also helps firms to explore new market segment and new customer in order to boost the revenues. Strategic focus of outsourcing serves as a measure of the extent to which a firm engages to improve company focus on core competencies to develop new product and explore new market. Thus this variable proposes two components of hypotheses related to company focus on core activities.

\section{1) New product Development}

New product development refers to the degree to which a firm is able to produce new product by utilizing its core resources while appropriating its non-core activities through outsourcing. Outsourcing leads to a firm to concentrate on R\&D by transferring less important activities to others that ultimately result in new product development (Boehe, 2010). Besides, in some cases, where there is risk involved with the development of the new product, firms may outsource to a specialized service provider that has up to date knowledge and a strong focus which result in quality product with lower cost (Welch \& Nayak ,1992). Consequently, we can propose the following hypothesis.

Hypothesis H2.1: Opportunity of New product development has influence in second-order outsourcing decision.

\section{2) Explore new market segment}

Explore new market refers to the degree to which a firm is able to exploring the market opportunities and access those opportunities for its new product and service. If there is a gap in a market for any particular product or service, and if there are buyers, a company can just go ahead and fill that gap by bringing that product or service into that market segment. By outsourcing to another country, a company can access suppliers as new destination for export market as well as outsourcing firm's developed market (Bertrand, 2010). Consequently, we can propose the following hypothesis.

\section{Hypothesis H2.2: Opportunity of New market segment has influence in second-order outsourcing decision.}

\subsubsection{Access to Missing Capability}

Not all firms have all of the resources and capabilities that are essential to produce its product and service. However, resources and capabilities can be accessible from other firms by making strategic alliances i.e. outsourcing. Outsourcing allows firm to make partnership relationship with others that result in filling the resource gap. This variable proposes three components (such as availability of specialist, superior technology, and established tools and support infrastructure) of hypotheses that allow large manufacturing firms access to the missing capability. This variable is measured by investigating the factors on how outsourcing allows firms to access to the suppliers' capabilities, superior technologies, and established tools and techniques that could produce higher productivity and profit earnings as well. Outsourcing to certain second order SMEs can allow access to particular expertise developed by these SMEs suppliers.

\section{1) Availability of Specialist}

Firms may lack of specialists and able to fulfill this gap by sourcing from others firms. If the outsourcing firms have no enough IT experts, then they can seek for third parties IT expert to fulfill this gap. For example, some large manufacturing firms are not good in all areas of outsourcing activities, however, some other small and 
medium supplier are specialized in some areas of their core functions. Therefore, second-order outsourcing allows large manufacturing firms to access those best specialists of other suppliers who have hands-on experiences in non-core activities of focal firms (Rashid \& Azad, 2013). Consequently, we can propose the following hypothesis.

Hypothesis H3.1: Access to availability of specialist of other suppliers has influence in second-order outsourcing decision.

2) Superior Technology

Technology is always changing, and usually at a rapid pace. However, firms may not have up-to-date technology or capacity to do their business functions. Suppliers would have superior technology considering that the suppliers are specific in the core activities (Alderete, 2013). These up-to-date technologies give other small and medium suppliers competitive advantages to compete with rivals that add value to their product or services. Therefore, second-order outsourcing allows large manufacturing firms to access those superior technology and high efficiency of supplier firms that produce better quality product and service. Consequently, we can propose the following hypothesis.

Hypothesis H3.2: Access to superior technology of other suppliers has influence in second-order outsourcing decision.

3) Established tools and support infrastructure

Like latest and high efficiency technology, suppliers would have equipped technology, established tools, and supporting infrastructure to execute their business. Some suppliers possess established tools and support infrastructure (like well-established training and development plan) that allowsthem to provide better business transactions and customer supports. By sub-contracting to the second order suppliers, a firm may access to those kind of missing capability from partner firms. Consequently, we can propose the following hypothesis.

Hypothesis H3.3: Access to established tools and support infrastructure of other suppliers has influence in second-order outsourcing decision.

\subsubsection{Internal Resources constraints}

In manufacturing industry, majority of the companies outsource to other manufacturing firms due to inadequate internal resources that impede smooth operation of their production activities. Here, outsourcing may allow large manufacturing firms to fill this gap by utilizing supplier production capacity and technical experts to meet the customer requirements. This variable proposes two components of hypotheses.

1) Limited Production and Space Capacity

Manufacturing firms may not have all required production capacities to fulfill the agreement in proper time. In high time, usually firms receive more orders that they can handle with their existing infrastructure. In such case, manufacturing process could be hampered if the manufacturing firms have no adequate production capacity. As a consequence, they transfer part of the production process to other manufacturing firms or access their production and space capacity. On the other hand, firms may create production and space flexibility by outsourcing non-core activities to other supplier. This may also allow firms to shift these idle capacities to core-business areas or support upstream customer demands. Consequently, we can propose the following hypothesis.

Hypothesis H4.1: Limited production and space capacity of large companies has influence in second-order outsourcing decision.

2) Inadequate Technical Expert and Support Infrastructure

Like production and space capacity, outsourcing also allows manufacturing firm to access other firms' technical expert and infrastructure facilities if they lack these kinds of resources. Thus, the unavailability of support infrastructure could also be solved by seeking external providers' solution. Consequently, we can propose the following hypothesis.

Hypothesis H4.2: Inadequate technical expert and support infrastructure of large companies has influence in second-order outsourcing decision.

\subsection{Second-order Outsourcing Decision}

The dependent variable of this study would be measured in terms of the consideration of outsourcing decision. Outsourcing decision could be the first step to increase profitability or improve the competitive position of the company. In this study, we measure 'second-order' outsourcing decision based on manufacturing firms' economic factors, strategic factors, and resource factors. Economic factors refers to the manufacturing firms 
financial benefits that derives from outsourcing process, strategic factor is related to strategic company focus that allow them to develop their existing business, and finally resource factor denotes the firms internal resources, organizational boundary and complementarities of internal and external resources for improving the organizational performance. We measure this variable based on the items developed by Greaver (1999), where outsourcing decision derives from the economic sense and inadequacy of business capabilities. Others factor may also important for outsourcing decision including: entering and managing a long-term relationship with suppliers and exposing vital organizational assets to the control of external agents. Furthermore, the benefits of outsourcing derive from the maturity of the companies in planning for strategic advantage and position in competitive market environment.

\section{Research Design and Methodology}

\subsection{Sample Selection and Operationalization of Constructs}

We have used survey method to collect the data from the target respondents and test the proposed research model and hypotheses. Our respondents are managers of big size manufacturing firms in Bangladesh who take order from the foreign clients, and further take decision to redistribute the outsourcing activities among the local small and medium size manufacturing firms. The role of target respondents was to provide key information on an aggregated unit of analysis from the organizational or group viewpoint rather than personal attitude and perception. Moreover, we choose the managers who have at least some kinds of responsibility to take strategic outsourcing decision.

A simple questionnaire was developed where measures of the constructs were adopted from previous studies (Burkholder, 2005; Sood, 2006; Smith et al., 1998; Bocij et al., 2006; Welch \& Nayak, 1992). These studies explored a numbers of factors that influence focal firms' outsourcing decision to second order suppliers. We adopted our measure from previous studies, because these measures are previously tested and validated. The dependent variable, second-order outsourcing decision, was measured based on the operational, strategic, and economic benefits arise from manufacturing outsourcing decisions. A 42 items survey questionnaire was developed to obtain the data from the outsourcing firms. After developing the questionnaire, we undertook cognitive survey test with researchers and practitioners for adjusting the questionnaire. The questionnaire was pretested through a pilot study to ensure the validity, reliability and understanding constructs of the instruments. Based on the pilot test results and recommendations from the researchers, we revised the questionnaire before being put into the final form. The final questionnaire was consisted of 38 items, where each item was measured on a five-point Likert scale from 'strongly disagree' to 'strongly agree'.

\subsection{Data Collection and Sample Characteristics}

The aim of this study was to analyze the factors influencing 'second order' outsourcing decision of large manufacturing firms to other suppliers in Bangladesh. To fulfil our research objective, we set target respondents as mid-level executives from large manufacturing outsourcing firms in Bangladesh. A total of 280 questionnaires were distributed among the managers of manufacturing firms who deal with the foreign buyers and subsequently take some kinds of responsibility to second-orders outsourcing decision. We first contacted official of BEPZA (Bangladesh Export Processing Zones Authority), and selected the firms who followed in our research objectives. We then distributed the questionnaire to the selected managers of manufacturing firms through non-sampling approach because of its inexpensiveness and less time consuming benefits. The questionnaires were distributed through the social and business network of the researchers through personal contact and referrals. After 15 days of first distribution of questionnaire, we reminded them for their responses. A total of 131 questionnaires were collected out of a 280 questionnaires where 5 questionnaires were discarded due to insufficient information. Therefore, the total numbers of useable responses were 126 which made up of $45 \%$ response rate.

Among the 126 responses, $59 \%$ of the respondents were male and rest of are female (52). Out of 126 respondents 45 were from the age group of 31-40 years old. Approximately one third of the respondents were from the management level in charge of production (41\%). 82\% companies have experience 5 years or more in offshore outsourcing, where half of the companies have more than 200 employees and only 18 companies have more than 1000 employees. Table 1 shows the detail of profile of survey samples. 
Table 1. Summary of samples

\begin{tabular}{|c|c|c|c|}
\hline Factors & Categories & Frequency & Percentage $(\%)$ \\
\hline \multirow{2}{*}{ Gender } & Male & 74 & $58.7 \%$ \\
\hline & Female & 52 & $41.3 \%$ \\
\hline \multirow{4}{*}{ Age (Years) } & 21-30 years & 28 & $22.2 \%$ \\
\hline & $31-40$ years & 45 & $35.7 \%$ \\
\hline & $41-50$ years & 30 & $23.8 \%$ \\
\hline & More than 50 years & 23 & $18.3 \%$ \\
\hline \multirow{2}{*}{ Marital status } & Single & 57 & $45.2 \%$ \\
\hline & Married & 68 & $54.8 \%$ \\
\hline \multirow{4}{*}{ Education } & Diploma & 25 & $19.8 \%$ \\
\hline & Bachelor & 34 & $27.0 \%$ \\
\hline & Masters & 46 & $36.6 \%$ \\
\hline & Other & 21 & $16.7 \%$ \\
\hline \multirow{4}{*}{ Occupation } & Non-management & 20 & $15.9 \%$ \\
\hline & Executive & 37 & $29.4 \%$ \\
\hline & Management & 51 & $40.5 \%$ \\
\hline & Other & 18 & $14.3 \%$ \\
\hline \multirow{4}{*}{ Years of work experience } & Less than 5 years & 22 & $17.5 \%$ \\
\hline & 5-10 years & 48 & $38.1 \%$ \\
\hline & $11-15$ years & 34 & $27.0 \%$ \\
\hline & More than 15 years & 22 & $17.5 \%$ \\
\hline \multirow{5}{*}{ No. of employees in the organization } & Less than 100 & 28 & $22.2 \%$ \\
\hline & $101-200$ & 36 & $28.6 \%$ \\
\hline & $201-500$ & 25 & $19.8 \%$ \\
\hline & $501-1000$ & 19 & $15.1 \%$ \\
\hline & More than 1000 & 18 & $14.3 \%$ \\
\hline
\end{tabular}

\section{Data Analysis and Results}

\subsection{Validity and Reliability of Measurement Scale}

Table 2. Results of descriptive statistics and measurement validation

\begin{tabular}{|c|c|c|c|c|c|c|}
\hline Variables & Items & Mean & S.D & $\begin{array}{l}\text { Eigen } \\
\text { Value }\end{array}$ & $\alpha$ & Loadings \\
\hline Investment in Capital Machineries & 3 & 4.54 & 1.11 & 2.97 & 0.867 & $0.732,0.852,0.634$ \\
\hline Fixed and Variable cost & 4 & 4.62 & 1.09 & 2.86 & 0.763 & $0.735,0.812,0.812,0.823$ \\
\hline Floor Space Utilization & 3 & 5.32 & 1.13 & 2.46 & 0.810 & $0.682,0.791,0.845$ \\
\hline New Product Development & 3 & 4.42 & 1.03 & 3.23 & 0.774 & $0.765,0.784,0.723$ \\
\hline Explore New Market Segment & 4 & 5.27 & 1.25 & 4.32 & 0.872 & $0.718,0.834,0.872,0.838$ \\
\hline Availability of Specialist & 3 & 5.23 & 1.22 & 3.43 & 0.729 & $0.766,0.835,0.923$ \\
\hline Superior Technology & 3 & 5.44 & 1.31 & 4.36 & 0.923 & $0.932,0.832,0.912$ \\
\hline $\begin{array}{l}\text { Established Tools and Support } \\
\text { Infrastructure }\end{array}$ & 3 & 5.11 & 1.21 & 3.11 & 0.842 & $0.923,0.748,0.743$ \\
\hline $\begin{array}{l}\text { Limited Production and Space } \\
\text { Capacity }\end{array}$ & 4 & 4.97 & 1.10 & 3.56 & 0.847 & $0.823,0.763,0.678,0.877$ \\
\hline Inadequate Technical Experts & 3 & 4.89 & 1.06 & 4.10 & 0.755 & $0.836,0.792,0.838$ \\
\hline Second-order Outsourcing Decision & 5 & 5.23 & 1.22 & 4.55 & 0.854 & $0.893,0.914,0.823,0.852,0.919$ \\
\hline
\end{tabular}

To assess the validity and reliability of measurement scale, we examine the content validity; construct validity, and reliability. Content validity was assessed by examining the process by which scale items were generated, 
including extensive literature review and in-depth interviews conducted with the business executives and researchers. The purpose of construct validity is to show that items measure what they purport to measure. Uni-dimensionality was established with explanatory factor analysis; where 0.30 is generally consider being the lowest significant factor loading to define the construct (Hair et al., 1998). To analyze the internal consistency among the items of a construct Cronbach's alpha $(\alpha)$ is used as suggested by the researchers (Nunally, 1978). A point of 0.7 or more is an acceptable threshold for internal consistency, though there is no cut-off value for acceptance range. Our analysis shows all the values are larger than 0.7 , indicating all the variables have internal consistency. Table 2 demonstrates that all variables have an acceptable level of internal consistency, and Eigen value greater than 1 , indicating all factors have correlation and high reliability in data consistency.

\subsection{Correlation Analysis}

We measure the degree of relationship between the variables of the constructs and the dependent variable by Pearson-correlation-matrix. From table 3, the result of correlation matrix shows that all dimensions have positive linear relationship with offshore outsourcing decision, representing significant correlation with p- value less than 0.05. In addition, results also show that there are five dimensions which have strong relationship with second-order outsourcing decision. They are new product development, explore new market segment, superior technology, availability of specialist, and inadequate technical experts, since their values of ' $r$ ' are higher than 0.7. The other dimensions have moderate relationship with offshore outsourcing decision since their values of ' $r$ ' are between 0.3 and 0.7 .

Table 3. Correlations between independent variables and dependent variable

\begin{tabular}{|c|c|c|c|}
\hline Factors & $\begin{array}{l}\text { Pearson } \\
\text { Correlation }\end{array}$ & Factors & $\begin{array}{l}\text { Pearson } \\
\text { Correlation }\end{array}$ \\
\hline $\begin{array}{l}\text { Investment in } \quad \text { Capital } \\
\text { Machineries }\end{array}$ & $0.467^{* *}$ & Availability of Specialist & $0.742 * *$ \\
\hline Fixed and Variable cost & $0.526^{* *}$ & Superior Technology & $0.749 * *$ \\
\hline Floor Space Utilization & $0.354 * *$ & $\begin{array}{l}\text { Established Tools and Support } \\
\text { Infrastructure }\end{array}$ & $0.523^{* *}$ \\
\hline New Product Development & $0.765^{* *}$ & Limited Production and Space Capacity & $0.678^{* *}$ \\
\hline Explore New Market Segment & $0.834 * *$ & Inadequate Technical Experts & $0.821^{* *}$ \\
\hline
\end{tabular}

\subsection{Findings from the Study}

Table 4. Regression analysis for second-order outsourcing decision

\begin{tabular}{lllll}
\hline Variable & $\mathrm{B}$ & $\beta$ & $\mathrm{t}$ & $\mathrm{p}$ \\
\hline Constant (Bo) & 1.012 & & 0.892 & 0.374 \\
Investment in Capital Machineries (B1) & -0.042 & -0.045 & -0.553 & $\mathbf{0 . 5 7 1}$ \\
Fixed and Variable cost (B2) & 0.028 & 0.031 & 0.366 & $\mathbf{0 . 7 1 5}$ \\
Floor Space Utilization (B3) & 0.053 & 0.045 & 0.549 & $\mathbf{0 . 5 8 4}$ \\
New Product Development (B4) & 0.359 & 0.352 & 4.266 & 0.000 \\
Explore New Market Segment (B5) & 0.071 & 0.064 & 0.176 & $\mathbf{0 . 5 9 2}$ \\
Availability of Specialist (B6) & 0.225 & 0.232 & 2.592 & 0.026 \\
Superior Technology (B7) & 0.093 & 0.053 & 0.568 & $\mathbf{0 . 6 1 2}$ \\
Established Tools and Support Infrastructure (B8) & 0.142 & 0.185 & 2.068 & 0.032 \\
Limited Production and Space Capacity (B9) & 0.463 & 0.472 & 5.531 & 0.000 \\
Inadequate Technical Experts (B10) & 0.158 & 0.175 & 2.189 & 0.031 \\
R Square & 0.592 & & & \\
R & 0.655 & & & \\
Durbin Watson & 1.621 & & & \\
F & 39.632 & & & $0.000^{* *}$ \\
\hline
\end{tabular}

This study uses Linear Regression Analysis (LRA) to analysis the relationship between 10 predictors 
(independent) variables and outcome (dependent) variable. The dependent variable (second-order outsourcing decision) was projected by 10 independent variables of firms internal and external factors such as investment in capital machineries, fixed and variable cost, floor space utilization, new product development, explore new market segment, availability of specialist, superior technology, established tools and support infrastructure, limited production and space capacity and inadequate technical content expert. The analysis of regression indicates that regression model incorporates the 10 factors as predictors of second-order outsourcing decision:

$$
\begin{gathered}
\mathrm{Y}=1.012-0.042 * \mathrm{LCI}+0.028 * \mathrm{LFVC}+0.053 * \mathrm{~S}+0.359 * \mathrm{NPD}+0.201 * \mathrm{ENM}-0.025 * \mathrm{AS}+0.181 * \mathrm{LHET}+ \\
0.142 * \mathrm{ETSI}+0.463 * \mathrm{LPCS}+0.158^{*} \mathrm{LTSSI}
\end{gathered}
$$

The above table shows the regression analysis results of dependent and independent variables. The model shows the R square value of this study is 0.592 which indicates that this model explains approximately $59.2 \%$ variance of second-order outsourcing decision. The results of regression analysis reveal that among the decision variables 5 variables (new product development, availability of specialist, limited production and space capacity, established tools and support infrastructure, and inadequate technical experts) shown significant effect in second-order outsourcing decision at $5 \%$ significance level, however, remaining variables are not supported by the data such as capital investment $(\mathrm{p}=0.571)$, overhead and fixed cost $(\mathrm{p}=0.715)$ space $(\mathrm{p}=0.584)$ variables, explore new market segment $(\mathrm{p}=0.592)$ and superior technology $(\mathrm{p}=0.612)$. The largest beta coefficient is shown by limited- production and space capacity $(\mathrm{B} 9=0.463)$, which indicates that this variable makes the strongest unique contribution to explain the independent variable. The ANOVA analysis $(\mathrm{F}=39.63, \mathrm{p}<0.001)$ shows the regression model to be statistically fit to the data. Moreover, this study has no auto-correlation problem in the data as the Durbin-Watson variable of the model is 1.621.

\section{Discussion}

Table 5. Summary of the results

\begin{tabular}{lll}
\hline Serial & Hypothesis & Result \\
\hline H1 & Operating Cost Reduction-> Second Order Outsourcing Decision & Not-Supported \\
H1.1 & Investment in Capital machineries-> S. O. Outsourcing Decision & Not-Supported \\
H1.2 & Fixed and Variable cost-> S.O. Outsourcing Decision & Not-Supported \\
H1.3 & Floor Space Utilization-> S.O. Outsourcing Decision & Not-Supported \\
H2 & Improve Company Focus-> Second Order Outsourcing Decision & Partially Supported \\
H2.1 & New Product Development-> S. O. Outsourcing Decision & Supported \\
H2.2 & Explore New Market Segment-> S. O. Outsourcing Decision & Not-Supported \\
H3 & Access to Missing Capabilities-> Second Order Outsourcing Decision & Partially Supported \\
H3.1 & Availability of Specialist -> S.O. Outsourcing Decision & Supported \\
H3.2 & Superior Technology-> S. O. Outsourcing Decision & Not-Supported \\
H3.3 & Established Tools and Support Infrastructure -> S. O. Outsourcing Decision & Supported \\
H4 & Internal Resources Constraints-> Second Order Outsourcing Decision & Fully Supported \\
H4.1 & Limited Production and Space Capacity-> S.O. Outsourcing Decision & Supported \\
H4.2 & Inadequate Technical Experts -> S.O. Outsourcing Decision & Supported \\
\hline
\end{tabular}

The aim of the study was to analyze the factors that influence manufacturing firms' decision to outsource part of their activities to second-order outsourcing suppliers. To do so, this study identifies the factors affecting the manufacturing firm at first, and then uses those factors as background of second-order decision factors to outsource certain non-core business functions, and show their integrated relationship to determine how outsource could benefit the manufacturing firms in terms of lower operating cost, improve company focus, flexibility and efficiency in contributing to company revenues profitably. The regression analysis results of this study found that among the hypotheses 5 hypotheses are supported. These are new product development (H2.1), availability of specialist (H3.1), established tools and support infrastructure (H3.3), limited production and space capacity (H4.1), and inadequate technical experts (H4.2), indicating these hypotheses have shown positive results for taking second-order outsourcing decision. The remaining 5 hypotheses are not supported such as H1.1, H1.2, H1.3, H2.2, and H3.2 indicating respondents disagree on investment capital machineries, fixed and variable cost and floor space utilization, explore new marker segment, and superior technology could be reduced by outsourcing (Table 5). The possible explanation of not supporting these hypotheses may be, operating cost 
reduction is not the main reason for developing country big manufacturing firms to outsource their activities to second-order suppliers. Another possible explanation may be, these manufacturing firms also have low operating cost activities, manufacturing plant, and other infrastructure but other reasons influence them to take outsourcing decision.

Based on the key findings it is clear that large manufacturing firms in developing country take 'second order' outsourcing decision due to lack of internal resources, missing capabilities, and company focus that are supported by the data. It also reveals that among the four main hypotheses operating cost reduction is not supported by the data, however, internal resource constraints is very important for manufacturing firms for second-order outsourcing decision, and other variable such as improve company focus, and access to missing capabilities have partial effect. Though, reduction of operation cost reduction was one of the most important factors in first-order outsourcing decision for develop countries firms, however, manufacturing firms in developing countries take outsourcing decision in-order-to fulfill the gaps they have in manufacturing process. This is the main difference between two kinds of outsourcing decisions that is led by second order outsourcing.

\section{Implications, Limitation and Future Research}

The findings of this study have significant implications for research and practice. First, the previous researches mostly focused on outsourcing decision to first tier suppliers, however, the current study explored the factors behind the second-order outsourcing decisions of big suppliers (in developing country) to small and medium size firms had not been evident in the literature. Thus, this study extends the existing literature of offshore outsourcing by exploring the factors that influence the manufacturing firms' decision to outsource part of their received activities to other suppliers. Secondly, this study integrates variables from all of the decision areas of focal outsourcing firms and constitutes a conceptual model that shows significant impact on second-order outsourcing decision. Therefore, this study accumulated knowledge from diversified areas such as strategic, operational, and organizational boundaries, and enhanced the existing knowledge repository of outsourcing business.

This study also offers useful guidelines for the practitioners for making strategic decision to outsource their less or non-core activities to other smaller manufacturing firms. First, this is very important situation because small and medium firms in developing country have no enough infrastructures to receive order from foreign buyer in a competitive market, rather depend on the local big manufacturing firms for their outsourcing order. In this case, managers of large manufacturing firms can be benefited from these findings through outsourcing decision to small and medium firms, and concentrate their core business activities. Second, managers of focal firms may consider these findings for making their own decision to outsourcing their activities to manufacturing firms. In most cases, these variables are interchangeable and similar to both of focal and first-order manufacturing firms in developing country. Therefore, focal firms' managers can be benefited from the findings of this study.

As most of research this study too is not free from some limitations that have open opportunities for future research. First, this study has a small size (only 85) but it should be noted that only few big manufacturing firms take decision to outsource their received activities to other supplier firms. However, examining a large number of manufacturing firms may produce more accurate result of second-order outsourcing decisions. Therefore, future research can explore this study with large number of samples.

Second, this study is restricted to the Bangladeshi manufacturing firms, therefore, caution is needed while generalizing the findings in another developing country. Every country has different culture that regulates their business activities and decision making approach. So, one country decision factors may not produce same result in another country. Future research is recommended generalizing the results of this study to other outsourcing destination in Asia such as India, Vietnam, and Philippines or in other settings.

Third, this study only considers variable from operational, strategic, and organizational boundaries for taking decision to outsourcing, however, institutional policies and support infrastructure, and governmental regulations also influence the outsourcing decision of a country. This study skips these important variables that may produce different result. Next research may concentrate on these variables.

Finally, this study collected data only at a specific time with snapshot nature of outsourcing activities without considering the fact that these operational, strategic and organizational boundaries factors may changes over time Future research is recommended to consider the longitudinal type of study so that the changes these factors could be tracked.

\section{Conclusion}

The global offshore outsourcing market is growing exponentially. However, the factor behind firms' outsourcing 
decision changes with time, situation, strategy and competition in the global market. At once, cost savings was the only one reason for outsourcing to low cost countries; however, nowadays it confirms better quality products and services, higher firm performance, new product development, cost-savings and so on. Likewise, some companies in developing country consider further outsourcing decision since they receive more order beyond their capacities from the develop country firms, and execute by themselves and/or by others, transfer part of their manufacturing activities to other supplier firms. Sometimes, they act as an outsourcer or middleman in the global value chain. In this situation, some of their decision factors may or may not be similar to the focal firms' decision factors because two firms have different kinds of activities and business objectives.

This study raised the important issue of second-order outsourcing decision of large manufacturing firms in developing country by exploring the decision factors of outsourcing. Based on the four main factors (such as operating cost reduction, improve company focus, access to missing capabilities, and internal resource constraint) from the literature review, this study investigates not only the influential factors for second-order outsourcing decision but also make difference between develop and developing country firms decision factors for manufacturing outsourcing. It was not surprising to find that some variables are very important for develop country firms to take outsourcing decision, however, are not considered by developing country larger manufacturing firms in second-order outsourcing decision. Thus, this study explores some new insights for outsourcing researchers, and practitioners in developing country firms regarding second-order outsourcing decision for seeking way out due to the factors associated to their manufacturing limitations and affecting their profits.

\section{References}

Abidi, O., Su, Z., \& Mohiuddin, M. (2011). Strategic and Organizational Evolutions of High-Tech SME on Global Market. Chinese Business Review, 10(5), 327-339.

Alderete, M. V. (2013). Do information and communication technology access and innovation increase outsourcing in small and medium enterprises? JISTEM-Journal of Information Systems and Technology Management, 10(2), 303-322. http://dx.doi.org/10.4301/S1807-17752013000200007

Aron, R., \& Singh, J. V. (2005). Getting offshoring right. Harvard Business Review, 83(12), 135-143.

Azad, M., Al, S., \& Ahn, J. (2014). A Research Framework of Vendor Firms Body of Knowledge (Bok) and Its Impact On Offshore It Outsourcing Performance. Proceeding of the Pacific Asia Conference on Information Systems (PACIS-2014). Paper 308, Chendu, China. Retrieved from http://aisel.aisnet.org/pacis2014/308

Bertrand, O. (2010). What goes around comes around: Effects of offshore outsourcing on the export performance of firms. Journal of International Business Studies, 42(2), 334-344. http://dx.doi.org/10.1057/jibs.2010.26

Bettis, R., Bradley, S. P., \& Hamel, G. (1992). Outsourcing and industrial decline. Academy of Management Executive, 6(1), 7-22. http://dx.doi.org/10.5465/AME.1992.4274298

Bhagwati, J., Panagariya, A., \& Srinivasan, T. N. (2004). The muddles over outsourcing. Journal of Economic Perspectives, 18(4), 93-114. http://dx.doi.org/10.1257/0895330042632753

Bocij, P., Chaffey, D., Greasley, A., \& Hickie, S. (1999). Business Information Systems. Technology, Development and Management. London: FT.

Boehe, D. M. (2010). Captive offshoring of new product development in Brazil. Management International Review, 50(6), 747-773. http://dx.doi.org/10.1007/s11575-010-0054-z

Burkholder, N. C. (2006). Outsourcing: The definitive view, applications, and implications. NJ: John Wiley \& Sons.

Cheon, M. J., Grover, V., \& Teng, J. T. (1995). Theoretical perspectives on the outsourcing of information systems. Journal of information Technology, 10(4), 209-219. http://dx.doi.org/10.1057/jit.1995.25

Claver, E., González, R., Gascó, J., \& Llopis, J. (2002). Information systems outsourcing: Reasons, reservations, and success factors. Logistics Information Management, 15(4), 294-308. http://dx.doi.org/10.1108/0957 6050210436138

Cook, M. F., \& Gildner, S. B. (2008). Outsourcing Human Resources Functions. Retrieved from http://www.shrm.org/books/outsourcinghr2/excerpt.asp

Cynthia, A. K. (2004). Background on Business Services Outsourcing Testimony. Haas School Business, University of California Berkeley. Retrieved from http://staff.haas.berkeley.edu/kroll/pubs $/ \mathrm{State} \% 20$ testimony\%20030804.pdf

Daft, R. (1983). Organizational Theory and Design. Mason: South Western.

Davison, D. (2006). Top Ten Risks of Offshore Outsourcing. Meta Group Inc. Analyst Corner. Retrieved from http://www.zdnet.com/article/top-10-risks-of-offshore-outsourcing/ 
FAITC (Foreign Affairs and International Trade Canada). (2010). Linking to Global Value Chains: Guide for Small and medium-size Enterprises. Retrieved from http://www.tradecommissioner.gc.ca/eng/gvc-guide.jsp

Greaver, M. F. II. (1999). Strategic Outsourcing: A Structured Approach to Outsourcing Decisions and Initiatives. AMACOM Div: American Management Association.

Greer, C. R., Youngblood, S. A., \& Gray, D. A. (1999). Human resource management outsourcing: The make or buy decision. The Academy of Management Executive, 13(3), 85-96. http://dx.doi.org/10.5465/ame.1999. 2210317

Hairs, J. F., Anderson, R. E., Tatham, R. L., \& Black, W. C. (1998). Multivariate data analysis. Englewood Cliffs, NJ: Printice Hall.

Hsieh, C. T., \&Woo, K. T. (2005). The Impact of Outsourcing to China on Hong Kong's Labor Market. The American Economic Review, 95(5), 1673. http://dx.doi.org/10.1257/000282805775014272

Hummels, D., Ishii, J., \& Yi, K. M. (2001). The nature and growth of vertical specialization in world trade. Journal of International Economics, 54(1), 75-96. http://dx.doi.org/10.1016/S0022-1996(00)00093-3

Islam, M. A., Hoque, A., Mohiuddin, M., \& Su, Z. (2014). Analysis of Capital-Labor Productivity for Firm Level Total Productivity Performance of Pharmaceutical Industries in Developing Countries. Academy of Taiwan Business Management Review, 10(3), 20-27.

Kotabe, M., \& Murray, J. Y. (2004). Global sourcing strategy and sustainable competitive advantage. Industrial Marketing Management, 33(1), 7-14. http://dx.doi.org/10.1016/j.indmarman.2003.08.004

Lau, K. H., \& Zhang, J. (2006). Drivers and obstacles of outsourcing practices in China. International Journal of Physical Distribution \& Logistics Management, 36(10), 776-792. http://dx.doi.org/10.1108/096000306 10714599

Mohiuddin, M. (2011). Research on Offshore Outsourcing: A Systematic Literature Review. Journal of International Business Research (JIBR), 10(1), 59-76.

Mohiuddin, M., \& Su, Z. (2013a). Offshore Outsourcing and Competitive Advantage for Manufacturing SMEs: An Exploratory Study on Canadian Offshoring SMEs. Journal of Applied Business Research, 29(4), 1111-1130.

Mohiuddin, M., \& Su, Z. (2013b). Offshore Outsourcing of Core and Non-Core Activities and Integrated Firm-Level Performance: An Empirical Analysis on Québec Manufacturing SMEs. Journal of Management, 16(4), 454-478. http://dx.doi.org/10.3917/mana.164.0454

Nunally, J. C. (1978). Psychometric Theory (2nd ed.). New York: McGraw-Hill.

Quinn, J. B. (2000). Outsourcing innovation: the new engine of growth. Sloan Management Review, 42(4), 13-28.

Rashid, M. M., \& Al-Azad, M. S. (2013). Relocating Low-to-Medium Tech Manufacturing Activities to Developing Countries: Empirical Analysis of Taiwanese and South Korean Manufacturing Outsourcing to Bangladesh. Transnational Corporations Review, 5(2), 16-29.

Rashid, M. M., Al-Azad, M. S., Mohiuddin, M., \& Su, Z. (2014). Offshore outsourcing from emerging to least developing countries (LDCs): Decision factors of East-Asian manufacturing firms' relocation to Bangladesh. Proceeding of ASAC conference 2014. Muskoka, Ontario, Canada. Retrieved March 18, 2014, from http://www.asac.ca:80/files/vol-35,-2014/Proceedings--InternationalBusiness.pdf

Sen, S., \& Zhu, G. (1996). The optimal degree of outsourcing. Journal of Financial and Strategic Decisions, 9(3), 63-70. Retrieved from http://www.financialdecisionsonline.org/archive/pdffiles/v09n3/sen.pdf

Smith, M. A., Mitra, S., \& Narasimhan, S. (1998). Information systems outsourcing: A study of pre-event firm characteristics. Journal of Management Information Systems, 15(2), 61-93.

Sood, R. (2006). IT, Software and Services: Outsourcing \& Offshoring: The Strategic Plan with a Practical Viewpoint. Austin: AiAiYo Books LLC.

Welch, J., \& Nayak, P. (1992). Strategic sourcing: A progressive approach to make or buy decision. Academy of Management Executive, 6(1), 23-31. http://dx.doi.org/10.5465/AME.1992.4274302

\section{Copyrights}

Copyright for this article is retained by the author(s), with first publication rights granted to the journal.

This is an open-access article distributed under the terms and conditions of the Creative Commons Attribution license (http://creativecommons.org/licenses/by/3.0/). 